\title{
Expression of EpCAM in uveal melanoma
}

\author{
Danilo N Odashiro 1,2,3, Alexandre N Odashiro*1,2,3,4, Patrícia R Pereira1,2,3, \\ Katyanne Godeiro ${ }^{1,2}$, Emilia Antecka1 ${ }^{1}$, Sebastian Di Cesare ${ }^{1}$ and \\ Miguel N Burnier Jr${ }^{1}$
}

\author{
Address: ${ }^{1}$ Henry C. Witelson Ocular Pathology Laboratory, McGill University, Montreal, QC, Canada, ${ }^{2}$ Department of Ophthalmology, Federal \\ University of São Paulo (UNIFESP), São Paulo, Brazil, ${ }^{3}$ LAC-Pathology and Cytopathology Laboratory, Campo Grande, MS, Brazil and \\ ${ }^{4}$ Universidade para o Desenvolvimento do Estado e Região do Pantanal (UNIDERP) - Campo Grande, MS, Brazil \\ Email: Danilo N Odashiro - daniloodashiro@yahoo.com; Alexandre N Odashiro* - alexandrenakao@yahoo.com.br; \\ Patrícia R Pereira - patriciarusa@yahoo.com.br; Katyanne Godeiro - katyannegodeiro@hotmail.com; Emilia Antecka - emilia.antecka@mcgill.ca; \\ Sebastian Di Cesare - sebastian.dicesare@mail.mcgill.ca; Miguel N Burnier - miguel.burnier@mcgill.ca \\ * Corresponding author
}

Published: 24 November 2006

Cancer Cell International 2006, 6:26 doi:10.1 186/1475-2867-6-26

This article is available from: http://www.cancerci.com/content/6/1/26

(c) 2006 Odashiro et al; licensee BioMed Central Ltd.

This is an Open Access article distributed under the terms of the Creative Commons Attribution License (http://creativecommons.org/licenses/by/2.0), which permits unrestricted use, distribution, and reproduction in any medium, provided the original work is properly cited.
Received: 17 October 2006

Accepted: 24 November 2006

\begin{abstract}
Background: Uveal melanoma (UM) is the most common primary intraocular malignant tumor in adults, and nearly $40 \%$ of UM will develop metastasis that will ultimately lead to death. The Epithelial Cell Adhesion Molecule (EPCAM) is a type I transmembrane glycoprotein expressed by carcinomas of head and neck, ovary, colon, breast, kidney and lung. Recently, antibodies against EpCAM such as Edrecolomab and Catumaxomab were developed, and clinical trials with these antibodies have been used in several types of neoplasia. We studied the expression of EpCAM in UM.
\end{abstract}

Methods: 25 enucleated formalin-fixed, paraffin-embedded UM specimens were immunostained for EpCAM. Histopathological analysis of the specimens with regards to prognostic factors such as cell type, largest (linear) tumor dimension, number of mitotic figures, scleral invasion and tumor infiltrating lymphocytes were done.

Results: None of them was positive for this EPCAM.

Conclusion: In our report, UM did not express EpCAM. Therefore, it is not a helpful immunohistochemical marker to predict the behavior of UM. Further studies are needed to verify if EpCAM could also be related with prognosis and treatment of UM.

\section{Background}

Uveal melanoma (UM) is the most common primary intraocular malignant tumor in adults and encompass nearly $85 \%$ of all ocular melanoma[1]. The worldwide incidence of UM is 5.3 to 10.9 cases per million population comprising about $4,25 \%$ of all melanomas[1]. Even with the progress of diagnosis and treatment methods, in the last 25 years the UM mortality is almost unaltered[1].
Nearly $40 \%$ of UM will develop metastasis that will ultimately lead to death; therefore, a better understanding of the cellular and molecular mechanisms of UM is essential in order to develop novel and specific drugs to prevent or treat UM metastasis. It has been postulated that the high malignancy of cutaneous[2] and uveal melanomas[3] could be connected with an increased cytokeratin expression, an epithelial cell marker. 
Novel drugs that target cell surface antigens, signalling pathways, or critical effector molecules are in evidence in cancer research. We previously demonstrated that the majority of UM are positive for C-kit, a tyrosine kinase receptor, and UM cells impressively decreased the proliferation and invasion rates when exposed to imatinib mesylate, the C-kit inhibitor[4].

The Epithelial Cell Adhesion Molecule (EpCAM) discovered in the early 1980's is a type I transmembrane glycoprotein encoded by the ga733-2 gene on chromosome 4 (locus $4 \mathrm{q}$ ). It is detected at the basolateral membrane of the majority of epithelial tissue such as simple, pseudoestratified and transitional epithelium. However, in mature squamous stratified epithelium and in hepatocytes, EPCAM is negative [5-10]. Prior studies reported that EpCAM express in a variety of epithelial neoplasias, like carcinomas of head and neck, ovary, colon, breast, kidney and lung[5,9,11]. EpCAM immunoreactivity was also found in squamous pre-malignant lesions[5].

Recently, antibodies against EpCAM such as Edrecolomab and Catumaxomab were developed. Clinical trials with these antibodies has been used in patients with Colon, Breast, Head and Neck, Ovary and Gastrointestinal carcinomas [11-15].

Until now, immunoreactivity against Ep-CAM has not been previously described in UM. The aim of this research is to study the expression of EpCAM in UM.

\section{Materials and methods}

UM specimens obtained by enucleation between 1980 and 2004 were collected from the archives of the Henry C. Witelson Ocular Pathology Laboratory and Registry, McGill University, Montreal, Canada. Each specimen was formalin-fixed, paraffin-embedded and contained sufficient material for $\mathrm{H} \& \mathrm{E}$ and immunohistochemistry. Tumors presenting extensive necrosis that precluded an appropriate evaluation of histopathological features were excluded.

Histopathological analysis of the specimens with regards to prognostic factors such as cell type (modified Callender's classification) largest (linear) tumor dimension (LTD), number of mitotic figures in 40 high power fields (HPF) (400x), scleral invasion and tumor infiltrating lymphocytes (TIL) in 20 HPF were done. For the purpose of statistical analysis, tumors where classified as having a low mitotic rate (0-1 mitotic figures in $40 \mathrm{HPF})$ or a high mitotic rate ( 2 or more mitotic figures in $40 \mathrm{HPF}$ ). These parameters have been previously used in past studies. The presence of TIL was classified as low $(<200$ lymphocytes in $20 \mathrm{HPF}$ ) or high ( $>200$ lymphocytes in $20 \mathrm{HPF}$ ) according to a previous publication.
Immunohistochemistry was performed using the monoclonal anti-EpCAM antibody VU-1D9 (ab11293 - abcam, Cambridge, MA, USA). The antibody was applied at a dilution of $1: 70$ for $18 \mathrm{~h}$ at $4^{\circ} \mathrm{C}$, after 15 minutes in 10 $\mathrm{nmol} / \mathrm{l}$ citrate buffer ( $\mathrm{pH}$ 6.0) for antigen retrieval. Endogenous peroxidase was blocked using $0.3 \%$ hydrogen peroxidase diluted in methanol for 10 minutes. A standard avidin-biotin complex (ABC) technique using 3 amino-9 ethyl-carbazole was used for visualization. A case of colon adenocarcinoma was used as a positive control. Negative control sections were incubated with normal rabbit serum instead of the primary antibody.

After tissue processing, all cells that displayed distinct immunoreactivity were considered positive, regardless of intensity. Negative expression was determined by absence of the immunostain.

Statistical analysis was performed using a computer software (Statistical Package for the Social Sciences" version 11.5 (SSPS Inc., Chicago, IL, USA)). The categorical variables such as cell type (spindle or epithelioid), scleral invasion, mitosis $(0-1$ or $\geq 2$ in 40 HPF) and TIL $(0-200$ or $>$ 200 in $20 \mathrm{HPF}$ ) were analyzed. The chi-square test was used to assess statistical significance and a p value of less than 0.05 was considered significant.

\section{Results}

The results are displayed in table 1 .

Twenty-nine cases of UM were retrieved, and four cases were excluded due to extensive tumor necrosis. The 25 UM specimens studied presented the following cell types: 18 mixed, 5 epithelioid and 2 spindle. Scleral invasion was observed in $8 \%$ of the studied cases $(n=2)$. The tumor infiltrating lymphocyte index was low in $76 \%$ of the cases $(n=19)$ and high in $24 \%$ of the remaining cases $(\mathrm{n}=6)$. Approximately $56 \%$ of cases presented 2 or more mitotic figures in $40 \mathrm{HPF}(\mathrm{n}=14)$ and the remaining had 1 or less $(n=11)$. The mean average of the LTD was 9,9 $\mathrm{mm}$.

All the 25 specimens demonstrated negative staining to EpCAM. There was no expression of this protein in any part of the enucleated specimens (figure 1).

\section{Discussion}

EpCAM was described under several names originated from the respective monoclonal antibodies (KSA, ga7332, 17-1a antigen, mh99, aua 1, moc31) [5-8]. It mediates $\mathrm{Ca} 2+$ independent homotypic cell-cell adhesions and was correlated with the preservation of cellular adhesion [510]. Previous studies demonstrated that the overexpression of EpCAM had a negative efect on E-cadherin mediated cell-cell adhesion and upregulated the proto- 
Table I: The histopathological features of the UM cases.

\begin{tabular}{|c|c|c|c|c|c|c|}
\hline Case & Cell type & Scleral Invasion & TIL & Mitosis & LTD (mm) & EpCAM \\
\hline 1 & $M$ & $\mathrm{~N}$ & $\mathrm{~L}$ & $\mathrm{H}$ & 13 & Neg \\
\hline 2 & $M$ & $\mathrm{~N}$ & $\mathrm{~L}$ & L & 7 & Neg \\
\hline 3 & $M$ & $N$ & $\mathrm{~L}$ & $\mathrm{H}$ & 12 & $\mathrm{Neg}$ \\
\hline 4 & $M$ & $\mathrm{~N}$ & $\mathrm{~L}$ & $\mathrm{H}$ & 9 & $\mathrm{Neg}$ \\
\hline 5 & $E$ & $Y$ & $\mathrm{H}$ & $\mathrm{H}$ & 18 & $\mathrm{Neg}$ \\
\hline 6 & $M$ & $\mathrm{~N}$ & $\mathrm{~L}$ & $\mathrm{~L}$ & 5 & $\mathrm{Neg}$ \\
\hline 7 & $M$ & $\mathrm{~N}$ & $\mathrm{~L}$ & $\mathrm{~L}$ & 8 & $\mathrm{Neg}$ \\
\hline 8 & $M$ & $\mathrm{~N}$ & $\mathrm{~L}$ & $\mathrm{H}$ & 8 & $\mathrm{Neg}$ \\
\hline 9 & $M$ & $\mathrm{~N}$ & $\mathrm{~L}$ & L & 5 & $\mathrm{Neg}$ \\
\hline 10 & $E$ & $\mathrm{~N}$ & $\mathrm{H}$ & $\mathrm{H}$ & 14 & $\mathrm{Neg}$ \\
\hline 11 & $M$ & $\mathrm{~N}$ & $\mathrm{~L}$ & $\mathrm{~L}$ & 7 & $\mathrm{Neg}$ \\
\hline 12 & $M$ & $\mathrm{~N}$ & $\mathrm{~L}$ & L & 9 & $\mathrm{Neg}$ \\
\hline 13 & $M$ & $\mathrm{~N}$ & $\mathrm{~L}$ & $\mathrm{~L}$ & 9 & $\mathrm{Neg}$ \\
\hline 14 & $S$ & $\mathrm{~N}$ & $\mathrm{~L}$ & $\mathrm{~L}$ & 4 & $\mathrm{Neg}$ \\
\hline 15 & $M$ & $\mathrm{~N}$ & $\mathrm{H}$ & $\mathrm{H}$ & 12 & $\mathrm{Neg}$ \\
\hline 16 & $M$ & $\mathrm{~N}$ & $\mathrm{~L}$ & $\mathrm{H}$ & 13 & $\mathrm{Neg}$ \\
\hline 17 & $M$ & $\mathrm{~N}$ & $\mathrm{~L}$ & $\mathrm{H}$ & 11 & $\mathrm{Neg}$ \\
\hline 18 & $E$ & $Y$ & $\mathrm{H}$ & $\mathrm{H}$ & 16 & $\mathrm{Neg}$ \\
\hline 19 & $M$ & $\mathrm{~N}$ & $\mathrm{~L}$ & $\mathrm{~L}$ & 7 & $\mathrm{Neg}$ \\
\hline 20 & $M$ & $\mathrm{~N}$ & $\mathrm{~L}$ & $\mathrm{H}$ & 11 & $\mathrm{Neg}$ \\
\hline 21 & $E$ & $\mathrm{~N}$ & $\mathrm{H}$ & $\mathrm{H}$ & 13 & $\mathrm{Neg}$ \\
\hline 22 & $M$ & $\mathrm{~N}$ & $\mathrm{~L}$ & $\mathrm{~L}$ & 6 & $\mathrm{Neg}$ \\
\hline 23 & $S$ & $\mathrm{~N}$ & $\mathrm{~L}$ & $\mathrm{~L}$ & 4 & $\mathrm{Neg}$ \\
\hline 24 & E & $\mathrm{N}$ & $\mathrm{H}$ & $\mathrm{H}$ & 14 & $\mathrm{Neg}$ \\
\hline 25 & $M$ & $\mathrm{~N}$ & $\mathrm{~L}$ & $\mathrm{H}$ & 12 & $\mathrm{Neg}$ \\
\hline
\end{tabular}

TIL: tumor infiltrating lymphocytes; LTD: largest tumor dimension; M: mixed cell type; E: epithelioid cell tupe; S: spindle cell type; N: no; Y: yes; H: high; L: low; Neg: negative expression.

oncogene c-myc and cyclin A/E[16]. Based on these previous observations, EpCAM might be related with dediferentiation, proliferation and tumoral invasion $[5,16]$.

EpCAM is expressed in several types of epithelial tumors $[5,17]$. EpCAM overexpression is correlated with poor disease free suvival in breast cancer[18], and loss of EpCAM expression in gastric adenocarcinoma has been reported to be associated with poor TNM staging prognosis[10], although inconsistent[19]. It is also detected weakly and occasionally in types of cancer other than carcinoma as fibrosarcoma, angiosarcoma, amd estesioneuroblastoma[17].

Some cases of cutaneous melanoma stains for epithelial markers[20], and most of them are metastatic lesions[21], meaning, more aggressive tumors. Also, UM cases that express cytokeratin proteins, a phenomenon that have been called interconverted phenotype, are correlated with poor prognosis[3]. In such cases, EpCAM, as an epithelial antigen, could be expected to be positive. Further studies of EpCAM with known cytokeratin positive UM tumors could confirm if there is any relationship between EpCAM and UM.
The reason of testing EpCAM in UM is the anti-EpCAM drugs avaiable to treat some malignant tumors. Edrecolomab is a monoclonal Anti-EpCAM antibody (Co17-1A antigen). In studies using Edrecolomab as adjuvant therapy, there was elimination of bone marrow micrometastases from Breast cancer[13]. Also, Edrecolomab has been tested in patients with colon cancer stages II and III, but without improvement in overall or disease-free survival, even when added with fluorouracil and folinic acid[14,22].

Catumaxomab is a bispecific trifunctional antibody $(\operatorname{trAb})($ anti-EpCAM $\times$ anti-CD3) and belongs to a new class of intact antibodies. The two binding sites of this antibody are against EpCAM positive tumor cells and T cells (CD3+). At the same time, this is mediated by the Fcregion, which binds to Fc3 - receptors I and III on accessory cells (macrophages, natural killer cells, dendritic cells). This results in higher tumor killing than the monoclonal antibodies mentioned[11,12,15,23]. Recently, there are promising results with Catumaxomab in treatment of malignant ascites associated with Ovarian cancer, Non-small cell Lung Cancer and Peritoneal Carcinomatosis due to Gastrointestinal Cancer[12,15,23]. 


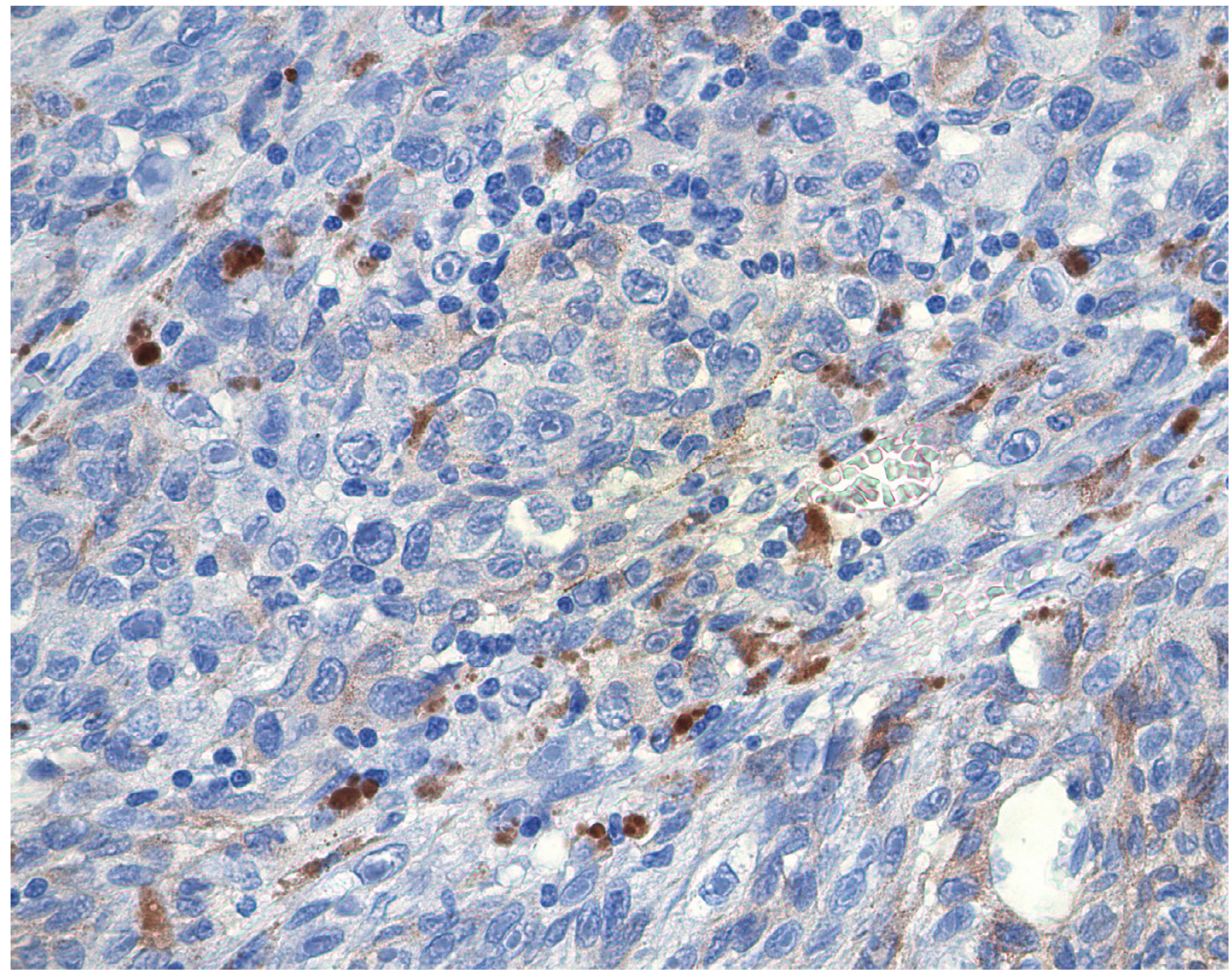

Figure I

Epithelioid pigmented melanoma cells showing no expression to EpCam by immunohistochemistry.

We made an effort to detect EpCAM expression in 25 selected cases of uveal melanoma; however, none of them were positive, even in the UM epithelioid cell type.

\section{Conclusion}

EpCAM is overexpressed in a variety of epithelial neoplasias. The development of adjuvant therapy targeted against EpCAM, in the future, may help increase patient survival in this set of patients. In our report, UM did not express EpCAM. Therefore, it is not a helpful immunohistochemical marker to predict the behavior of UM. Further studies are needed to verify if EpCAM could also be related with prognosis and treatment of UM.

\section{Authors' contributions}

DNO - wrote the manuscript
ANO - revised the histopathological characteristics of the UM cases

PRP and KG - revised the expression of EpCam in the UM cases

EA and SDC - responsible for the immunostains

$\mathrm{MB}$ - revised the entire manuscript.

\section{References}

I. Singh AD, Bergman L, Seregard S: Uveal melanoma: epidemiologic aspects. Ophthalmol Clin North Am 2005, I8:75-84, viii.

2. Korabiowska M, Ruschenburg I, Schulz H, Steinacker A, Bortkiewicz P, Sevenich M, Brinck U, Cordon-Cardo C, Fischer G: Cytokeratin expression correlates with aneuploidy in cytological specimens of melanoma metastases. Anticancer Res 2005, 25:2789-2792.

3. Hendrix MJ, Seftor EA, Seftor RE, Gardner LM, Boldt HC, Meyer M, Pe'er J, Folberg R: Biologic determinants of uveal melanoma 
metastatic phenotype: role of intermediate filaments as predictive markers. Lab Invest 1998, 78:153-163.

4. Pereira PR, Odashiro AN, Marshall JC, Correa ZM, Belfort R, Burnier $\mathrm{Jr} M N$ : The role of c-kit and Imatinib Mesylate in uveal melanoma. J Carcinog 2005, 4:19.

5. Winter MJ, Nagtegaal ID, van Krieken JH, Litvinov SV: The epithelia cell adhesion molecule (Ep-CAM) as a morphoregulatory molecule is a tool in surgical pathology. Am J Pathol 2003, 163:2139-2|48.

6. Balzar M, Winter MJ, de Boer CJ, Litvinov SV: The biology of the I7-I A antigen (Ep-CAM). J Mol Med 1999, 77:699-7I2.

7. litinov SVV Markwin P.;Bakker, Hellen A.M.Fleuren, Gert Jan, Warnaar, Sven O.: Ep-cam:A Human Epithelial Antigen Is a Homophilic Cell-Cell Adhesion Molecule. The Journal of Cell Biology 1994, I 25:437-446.

8. de Boer CJ, van Krieken JH, Janssen-van Rhijn CM, Litvinov SV Expression of Ep-CAM in normal, regenerating, metaplastic, and neoplastic liver. J Pathol I999, | 88:20|-206.

9. Osta WA, Chen Y, Mikhitarian K, Mitas M, Salem M, Hannun YA Cole DJ, Gillanders WE: EpCAM is overexpressed in breast cancer and is a potential target for breast cancer gene therapy. Cancer Res 2004, 64:58I8-5824.

10. Songun I, Litvinov SV, van de Velde CJ. Pals ST, Hermans I, van Krieken JH: Loss of Ep-CAM (COI7-IA) expression predicts survival in patients with gastric cancer. $\mathrm{Br} J$ Cancer 2005, 92: I767-I772.

II. Gronau SS, Schmitt M, Thess B, Reinhardt P, Wiesneth M, Schmitt A, Riechelmann $\mathrm{H}$ : Trifunctional bispecific antibody-induced tumor cell lysis of squamous cell carcinomas of the upper aerodigestive tract. Head Neck 2005, 27:376-382.

12. M. Sebastian AS H. Friccius-Quecke, F. Kanniess, R. Wiewrodt, $H$. Lindhoter, M. Jaeger and B. Passlick: P-974 Treatment of nonsmall cell lung cancer (NSCLC) patients with the trifunctional bispecific antibody catumaxomab (removab ${ }^{\circledR}$ ) (antiEpCAM $\times$ anti-CD3: Results of a phase I study. Lung Cancer 2005, Volume 49: S376.

13. Kirchner EM, Gerhards R, Voigtmann R: Sequential immunochemotherapy and edrecolomab in the adjuvant therapy of breast cancer: reduction of 17-|A-positive disseminated tumour cells. Ann Oncol 2002, 13:1044-1048.

14. Hartung G, Hofheinz RD, Dencausse Y, Sturm J, Kopp-Schneider A Dietrich G, Fackler-Schwalbe I, Bornbusch D, Gonnermann M, Wojatschek C, Lindemann W, Eschenburg H, Jost K, Edler L, Hochhaus A, Queisser W: Adjuvant therapy with edrecolomab versus observation in stage II colon cancer: a multicenter randomized phase III study. Onkologie 2005, 28:347-350.

15. P Wimberger*I AB V Gorbounova3, H Sommer4, B Schmalfeldt5,, Pfisterer6 ML A Makhson7, M Ströhlein8, W Eiermann9, M Biakhov 10 VM A du Bois 12 and R Kimmig I: Tolerability and efficacy of the trifunctional antibody removab ${ }^{\circledR}$ (anti-EpCAM $x$ anti-CD3) in patients with malignant ascites due to ovarian cancer: Results of a phase I/II study. Cancer Cell International 2004, 4(Suppl I)::S3.

16. Munz M, Kieu C, Mack B, Schmitt B, Zeidler R, Gires O: The carcinoma-associated antigen EPCAM upregulates c-myc and induces cell proliferation. Oncogene 2004, 23:5748-5758.

17. Went PT, Lugli A, Meier S, Bundi M, Mirlacher M, Sauter G, Dirnhofer $S$ : Frequent EpCam protein expression in human carcinomas. Hum Pathol 2004, 35: I22-1 28.

18. Spizzo G, Went P, Dirnhofer S, Obrist P, Simon R, Spichtin H, Maurer R, Metzger U, von Castelberg B, Bart R, Stopatschinskaya S, Kochl OR, Haas $P$, Mross F, Zuber M, Dietrich H, Bischoff S, Mirlacher $M$, Sauter G, Gastl G: High Ep-CAM expression is associated with poor prognosis in node-positive breast cancer. Breast Cancer Res Treat 2004, 86:207-2I3.

19. Joo M, Kim H, Kim MK, Yu HJ, Kim JP: Expression of Ep-CAM in intestinal metaplasia, gastric epithelial dysplasia and gastric adenocarcinoma. J Gastroenterol Hepatol 2005, 20:1039-1045.

20. Kim YC, Lee MG, Choe SW, Lee MC, Chung HG, Cho SH: Acral lentiginous melanoma: an immunohistochemical study of 20 cases. Int J Dermatol 2003, 42:123-129.

21. Ben-Izhak O, Stark P, Levy R, Bergman R, Lichtig C: Epithelia markers in malignant melanoma. A study of primary lesions and their metastases. Am J Dermatopathol 1994, 16:24I-246.

22. Punt CJ, Nagy A, Douillard JY, Figer A, Skovsgaard T, Monson J, Barone C, Fountzilas G, Riess H, Moylan E, Jones D, Dethling J, Colman
J, Coward L, MacGregor S: Edrecolomab alone or in combination with fluorouracil and folinic acid in the adjuvant treatment of stage III colon cancer: a randomised study. Lancet 2002, 360:67|-677.

23. M.Sebastian AS H Fficcius-Quecke, F Kannjess,, R Wiewrodt HL M Jaeger, B Passlick: Treatment of non-small cell lung cancer (NSCLC) patients with the trifunctional blspecific antibody catumaxomab(removab (B) (antl-EpCAM $x$ antl-CD3): Results of a phase I study. 2005
Publish with Bio Med Central and every scientist can read your work free of charge

"BioMed Central will be the most significant development for disseminating the results of biomedical research in our lifetime. "

Sir Paul Nurse, Cancer Research UK

Your research papers will be:

- available free of charge to the entire biomedical community

- peer reviewed and published immediately upon acceptance

- cited in PubMed and archived on PubMed Central

- yours - you keep the copyright 